PONTIFÍCIA UNIVERSIDADE CATÓLICA DO RIO DE JANEIRO

\title{
Gestão de Pessoas e a Geração Y
}

\author{
Luiza de Mello Martin
}

Trabalho de Conclusão de Curso

Centro de CiênCIAS SOCIAIS - CCS

DEPARTAMENTO DE AdMINISTRAÇÃO

Graduação em Administração de Empresas 


\section{Luiza de Mello Martin}

\section{Gestão de Pessoas e a Geração Y}

Trabalho de Conclusão de Curso

Trabalho de Conclusão de Curso, apresentado ao programa de graduação em Administração da PUC-Rio como requisito parcial para a obtenção do título de graduação em Administração.

Orientadora: Patrícia ítala 


\section{Agradecimentos}

Aos meus pais, Carlos e Luciana, por acreditarem na minha capacidade, dandome a oportunidade de estudar em uma excelente faculdade e apoiando-me durante toda a trajetória. A minha irmã, Carla, por ter me dado suporte durante a parte final da escrita.

Ao meu namorado, Igor Mello, por estar ao meu lado durante todo o desenvolvimento deste trabalho. Além do imenso apoio na difícil decisão de escolher o curso de administração no meio da faculdade de engenharia.

Aos meus amigos por toda ajuda, pelo carinho e por estarem comigo sempre.

A todos os professores que tive até hoje, em especial, a minha orientadora, Patrícia Ítala, por toda a dedicação, ajuda e paciência. 


\section{Resumo}

Martin, Luiza de Mello. Gestão de Pessoas e a Geração Y. Rio de Janeiro, 2018. 44 p. Trabalho de Conclusão de Curso - Departamento de Administração. Pontifícia Universidade Católica do Rio de Janeiro.

A Geração Y se consolida no mercado de trabalho, trazendo novos hábitos e perspectivas para o ambiente organizacional. Com isso, é importante que os profissionais da área de Gestão de Pessoas busquem entendê-la, e consequentemente, ter conhecimento nos processos de atração e retenção desses jovens. $O$ presente estudo tem como objetivo identificar quais práticas de Gestão de Pessoas são mais valorizadas pela Geração Y no mercado de trabalho e, para isso, foi realizada uma pesquisa de campo com profissionais dessa geração, moradores do estado do Rio de Janeiro e que possuem pelo menos dois anos de experiência no mercado de trabalho com carteira assinada

Palavras-chave

Geração Y. Gestão de pessoas. Mercado de trabalho.

\section{Abstract}

Martin, Luiza de Mello. People Management and Generation Y. Rio de Janeiro, 2018. 44 p. Course Completion Work - Administration Department. Pontifical Catholic University of Rio de Janeiro.

Generation $Y$ is consolidates itself in the job market while bringing new habits and perspectives for the organizational environment. That being said, it is crucial that professionals in the People Management seek to understand it and, as a consequence, successfully attract and retain these young people. The present study has the goal of identifying which practices of People Management are more valued by Generation $\mathrm{Y}$ in the job market. For this purpose, a field research was done with professionals of this generation as well as habitants of the Rio de Janeiro state who have at least two years of experience in the formal job market.

Keywords

Generation Y. People management. Job market. 


\section{Sumário}

1 Introdução 1

1.1. Contexto 1

1.2. Objetivo do estudo 2

1.3. Objetivos intermediários do estudo 2

1.4. Delimitação e foco do estudo 3

1.5. Relevância do estudo 3

2 Referencial teórico 5

2.1. As gerações 5

2.2. Geração Y no trabalho 7

2.3. Gestão de pessoas 9

2.3.1. Práticas de gestão de pessoas 10

2.3.1.1. Treinamento e desenvolvimento 11

2.3.1.2. Avaliação de desempenho 12

2.3.1.3. Remuneração e benefícios 13

2.3.1.4. Clima organizacional e qualidade de vida no trabalho 13

$\begin{array}{ll}\text { 2.3.1.5. Plano de carreira } & 14\end{array}$

3 Métodos e procedimentos de coleta e de análise de dados do estudo 16

3.1. Etapas de coleta de dados 16

3.2. Fontes de informação selecionadas para coleta de dados no estudo16

3.3. Procedimentos e instrumentos de coleta de dados utilizados no $\begin{array}{ll}\text { estudo } & 17\end{array}$

3.4. Formas de tratamento e análise dos dados coletados para o estudo 18

3.5. Limitações do estudo

4 Apresentação e análise dos resultados 19

4.1. Descrição e análise dos resultados 19

4.2. Descrição do perfil dos respondentes 19

4.3. Características da Geração Y 21 
5 Conclusões e recomendações para novos estudos 29

5.1. Conclusão 29

5.2. Sugestões e recomendações para novos estudos 31

6 Referências $\quad 32$

$\begin{array}{ll}\text { Apêndice } 1 & 35\end{array}$

\section{Lista de Tabelas}

Tabela 1: Idade dos respondentes. ........................................................ 19

Tabela 2: Gêneros dos respondentes..................................................... 20

Tabela 3: Grau de escolaridade. ........................................................... 20

Tabela 4: Curso de formação. .................................................................... 21

Tabela 5: Tipos de empresa................................................................ 21

Tabela 6: Quantidade de empresas em que já trabalhou. ............................... 22

Tabela 7: Duração da última/atual experiência profissional. ............................. 22

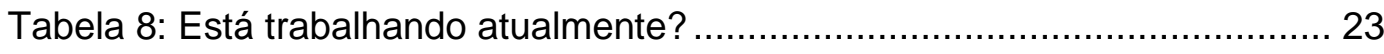

Tabela 9: Por qual(is) motivo(s) você sairia de sua atual empresa? ................. 23

Tabela 10: Por qual(is) motivo(s) você saiu do seu último emprego? ................ 24

Tabela 11: Treinamento e desenvolvimento................................................. 25

Tabela 12: Avaliação de desempenho........................................................ 26

Tabela 13: Remuneração e benefícios. ..................................................... 26

Tabela 14: Clima organizacional e qualidade de vida no trabalho. ................... 27

Tabela 15: Plano de carreira. .................................................................. 28

Tabela 16: Práticas de gestão de pessoas.................................................. 28

Tabela 17: Ordenação das práticas de gestão de pessoas. ............................. 29 


\section{Introdução}

\subsection{Contexto}

Em um ambiente cada vez mais turbulento e competitivo, a adaptação contínua das organizações passou a ser uma questão de sobrevivência e a velocidade desse processo, a condição necessária para agregar um diferencial competitivo (FISCHER; DUTRA; AMORIM, 2010). A tecnologia da informação trouxe desdobramentos imprevisíveis e transformou o mundo em uma verdadeira aldeia global. A competitividade tornou-se intensa e complexa entre as empresas. É a vez do conhecimento, do capital humano e do capital intelectual (CHIAVENATO, 2010). Esse quadro vem gerando grande pressão por novas formas de encarar a Gestão de Pessoas por parte das organizações (DUTRA, 2002).

A Administração de Recursos Humanos surgiu a partir do crescimento e da complexidade das tarefas organizacionais, como uma atividade mediadora entre as organizações e as pessoas. Visualizando as pessoas como recursos produtivos ou meros agentes passivos cujas atividades devem ser planejadas a partir das necessidades da organização. Hoje, a tendência nas organizações bem-sucedidas é de administrar com as pessoas. Ou seja, tratando-as como agentes ativos e proativos, dotados de inteligência e criatividade, de habilidades mentais e não apenas manuais ou físicas. As pessoas constituem um fator de competitividade, da mesma forma que o mercado e a tecnologia (CHIAVENATO 2004). A Gestão de Pessoas passou a administrar com as pessoas, como parceiros, e não meros recursos.

Nos últimos anos, as organizações cresceram de forma acelerada e absorveram um número grande de jovens para atuar em diferentes áreas e setores. Com isso as instituições perceberam a necessidade de se tornarem atrativas para esse novo público.

Diante desse contexto de mudanças, entender de cada geração passou a ser um fator primordial para a área de Gestão de Pessoas nas empresas. A Geração X, composta por indivíduos nascidos de 1965 a 1979 (CRAMPTON; HODGE, 2009) e especialmente a Geração Y, jovens nascidos entre 1980 e 1999 (OLIVEIRA, 2010), pois já ocupam posições de gerência ou estão iniciando 
sua trajetória profissional no mercado de trabalho e, portanto, começam a interferir de maneira mais direta no dia a dia da organização. Completando, o autor aponta que o destino da Geração $Y$ é o de modificar profundamente os paradigmas e premissas estabelecidos.

Segundo uma pesquisa feita pela consultoria Booz Allen Hamilton, 44\% da população economicamente ativa (PEA) mundial pertencerá à Geração $Y$ (nascidos entre 1980 e 1999) até 2025.

A área de Gestão de Pessoas se torna responsável, então, pela motivação e engajamento desses profissionais dentro do ambiente organizacional. Cabe a ela modificar antigas percepções e políticas internas para fazer com que esses colaboradores se sintam satisfeitos e ao mesmo tempo motivados à permanecerem na empresa.

Com o objetivo de compreender mais detalhadamente as expectativas dos profissionais, especificamente da Geração $\mathrm{Y}$, sobre práticas e fatores de Gestão de Pessoas, põe-se a seguinte questão para o presente estudo: Quais são as práticas de Gestão de Pessoas mais valorizadas pela Geração Y no ambiente organizacional?

\subsection{Objetivo do estudo}

Este trabalho tem como objetivo identificar as práticas relacionadas à Gestão de Pessoas mais valorizadas pela Geração $Y$ no ambiente organizacional.

Para atingir o objetivo será necessário descrever as características da Geração Y, compreender seu comportamento no ambiente corporativo, apresentar as atividades de Gestão de Pessoas dentro de uma empresa e realizar uma pesquisa de campo com profissionais dessa geração específica.

\subsection{Objetivos intermediários do estudo}

Para atingir o objetivo principal desse estudo, será necessário alinhar e, a seguir, descrever os objetivos intermediários:

a) Conceituar as gerações anteriores à Geração $Y$, além da mesma. Para identificar suas respectivas diferenças;

b) Compreender o comportamento e as expectativas da Geração Y no trabalho; 
c) Apresentar as atividades e práticas de Gestão de Pessoas, tais como treinamento e desenvolvimento, avaliação de desempenho, remuneração e benefícios, clima organizacional, qualidade de vida no trabalho e plano de carreira;

d) Compreender os motivos que levam essa geração a buscar novas oportunidades de trabalho.

\subsection{Delimitação e foco do estudo}

Restringe-se ao estudo identificar as práticas de Gestão de Pessoas mais valorizadas pela Geração Y no ambiente corporativo, levando em consideração os processos, como avaliação de desempenho, treinamento e desenvolvimento, processo de recrutamento e seleção, qualidade de vida no trabalho, remuneração e benefícios, plano de carreia e clima organizacional. O estudo será delimitado aos profissionais residentes do Rio de Janeiro, que trabalham ou trabalharam em regime formal, pelo menos por dois anos, graduados e que pertencem à Geração Y - delimitada segundo Oliveira (2010) pelas pessoas nascidas entre 1980 e 1999.

Não foi medido o nível de retenção dos profissionais da Geração $Y$ nas empresas que passaram ou que estão atuando atualmente, e também não foi levado em consideração o sucesso de carreira dos colaboradores da pesquisa.

A pesquisa foi feita no segundo semestre de 2018.

\subsection{Relevância do estudo}

Os recursos tecnológicos influenciaram os valores, os princípios e o comportamento da Geração $\mathrm{Y}$, exercendo um grande impacto em seus relacionamentos, envolvimento e desempenho - elementos fundamentais da política empresarial. Dessa forma, um dos grandes desafios para a gestão empresarial passou a ser o de lidar com os colaboradores pertencentes à essa geração (LIPKIN; PERRYMORE, 2010).

O estudo em questão pode contribuir com a atuação da área de Gestão de Pessoas nas organizações e os gestores, já que permitirá a identificação de fatores, julgados pela Geração Y, valiosos no ambiente corporativo. Auxiliando a desenvolver políticas para atender às necessidades, desejos e expectativas desses indivíduos, a fim de retê-los e motivá-los internamente. 
Há relevância também para os integrantes da Geração Y, pois o estudo contribui para a identificação das práticas de Gestão de Pessoas mais valorizadas por eles. Com isso, a busca por organizações que atendem suas expectativas será facilitada. 


\section{Referencial teórico}

Este capítulo do trabalho é dedicado à fundamentação teórica dos assuntos relacionados ao tema. O objetivo é sustentar as ideias apresentadas e esclarecer alguns conceitos.

A primeira seção irá abordar as definições e estudos acerca das gerações, contendo também os conceitos de três diferentes gerações. Os autores mencionados neste capítulo são referências acadêmicas nos temas. O segundo tópico será para descrever a relação entre a Geração $\mathrm{Y}$ e seu trabalho.

Na última parte será abordado o tema Gestão de Pessoas, contemplando suas práticas e a descrição de seis delas: Treinamento e Desenvolvimento, Avaliação de Desempenho, Remuneração e Benefícios, Clima Organizacional, Plano de Carreira e Qualidade de Vida no Trabalho.

\subsection{As gerações}

O contexto social em que uma geração cresceu impacta na personalidade, sentimentos em relação à autoridade, valores, crenças sobre as organizações, ética profissional e nas aspirações relacionadas à carreira destes indivíduos (SMOLA e SUTTON, 2002).

Usualmente uma geração pode compreender intervalos de 20 a 25 anos ou aproximadamente o tempo necessário para os indivíduos que compõem este grupo crescerem e se reproduzirem (STRAUSS e HOWE, 1991).

Alguns autores, que abordam o assunto gerações, divergem com relação aos períodos de cada geração, mas as características de cada uma não mudam significativamente.

Os baby boomers e a Geração X, compartilham com a Geração Y o mercado de trabalho atualmente, por isso serão abordados alguns aspectos dessas duas gerações. Além de um maior aprofundamento da Geração Y.

Segundo Smola e Sutton (2002), os baby boomers são chamados desta forma por conta do alto índice de nascimentos após a guerra, durante o período de 1946 e 1964. 
Este grupo é caracterizado como indivíduos que possuem maior tendência para manterem-se leais e vinculados a uma determinada organização (WONG, 2008).

Parte dessa geração já se aposentou e parte está perto de se aposentar, porém, os que trabalham, se encontram em níveis hierárquicos elevados dentro das organizações (LAB, 2010).

Logo após os baby boomers, surge a Geração X, que apresenta diferentes aspectos e características relacionadas ao ambiente organizacional e o mercado de trabalho. Para Smola e Sutton (2002) os indivíduos da Geração X cresceram entre grandes modificações, tradições e inseguranças familiares, financeiras e sociais. Segundo Alsop (2008) é composta por indivíduos nascidos entre os anos 1965 e 1979.

As pessoas que fazem parte do grupo da Geração $X$ são menos leais às organizações do que a Geração dos baby boomers, são considerados independentes e autossuficientes quando comparados às gerações anteriores (CRAMPTON e HODGE, 2009; WONG, 2008).

Em relação à geração anterior, os membros da Geração X têm maior probabilidade de deixar a organização por outro trabalho mais desafiador, por um salário mais elevado e/ou benefícios, tais como horário de trabalho flexível (CAVAZOTTE; LEMOS; VIANA, 2010).

Para Lipkin e Perrymore (2010), é possível encontrar gerações compartilhando o mesmo ambiente de trabalho, atualmente. Para os autores, o mais novo participante dessa diversidade de gerações é o da Geração Y.

Para Oliveira (2010) a Geração Y é composta por jovens nascidos entre 1980 e 1999 e, esses indivíduos se diferenciam consideravelmente das gerações anteriores (GLASS, 2007).

Essa geração é vista como uma das mais educadas, em relação a sua formação acadêmica, viajadas e com alta capacidade para lidar com a atual sofisticação tecnológica. Eles desejam trabalhar para viver e não viver para trabalhar (CRAMPTON e HODGE, 2009).

A Geração Y, também conhecida como Millennials, Geração da Internet e iGeração é a parcela mais jovem que está atuando hoje no mercado de trabalho (LIPKIN, PERRYMORE; MELO, 2010).

Os jovens dessa geração caracterizam-se como exibicionistas, individualistas, mas, por outro lado, apresentam um pensamento altamente altruísta, levando em consideração questões sociais e ambientais. São exploradores, inclinados à mudança de emprego com frequência, com o objetivo 
de atingir o ideal de carreira. (ALSOP, 2008). Para Oliveira (2010) essa geração é bastante conectada e sabe usufruir de toda tecnologia para obter relacionamentos mais numerosos e intensos. Conhecer pessoas de outras nacionalidades se tornou um passatempo comum, pois as redes sociais estão conseguindo universalizar todos os relacionamentos humanos. $O$ autor ainda complementa que, por privilegiar a ação individual e não a coletiva, esses jovens desenvolveram a necessidade de compartilhar parte de sua vida por meio das redes sociais.

Alguns autores mencionam sua expectativa por um rápido crescimento dentro das empresas, pelo desenvolvimento de suas competências e por um trabalho que tenha grande flexibilidade; trata-se de uma geração mais ativa socialmente do que a anterior, que teria preferência por atuar em empresas que preservem valores éticos e que sejam socialmente responsáveis (LOUGHLIN; BARLING, 2001; ALSOP, 2008; MUNRO, 2009).

Calliari e Motta (2012) ao compararem a Geração Y com as anteriores, alegam que os mesmos receberam mais oportunidades dos pais, tornando-os mais mimados. Para explicar esse fato, Oliveira (2010) entende que essa necessidade dos pais de oferecem aos seus filhos as melhores opções de escola, cursos, esportes diversificados, é uma forma de tentar compensar a presença deles no mercado de trabalho, por mais tempo, ou seja, sua ausência em casa. Os autores complementam que os mesmos exigem ambientes mais flexíveis, por conta da segurança exagerada dada pelos pais.

Esses jovens não possuem muita paciência, o que importa para eles é o resultado e não o processo para atingi-lo. Essa geração conhece o mundo em constante transformação e repleto de incertezas, esses fatos acabam não representando uma ameaça, pois, para eles, o mundo sempre foi configurado dessa forma. (TULGAN, 2009).

A seguir será detalhado um pouco mais sobre as características da Geração Y dentro do ambiente organizacional.

\subsection{Geração Y no trabalho}

Os jovens da Geração $Y$ representam os novos entrantes no mercado e estão ocupando os cargos das gerações anteriores, X e Babys Boomers (MELO; LEMOS, 2010)

São profissionais que almejam ter um rápido crescimento na empresa, querem adquirir mais responsabilidades, participar da parte mais estratégica e 
tomadas de decisão, mas, ao mesmo tempo, desejam desenvolver suas competências em ambiente de trabalho mais flexível (ALSOP, 2008).

O que motiva esses jovens não está exclusivamente atrelado ao fator financeiro, ou seja, remuneração e benefícios. Outras questões possuem também importância para eles, tais como: relacionamento com seu gestor, desenvolvimento pessoal e ambiente de trabalho. Mas, sem esquecer, que esses jovens gostam de ganhar dinheiro, e caso eles não recebam o que acreditam ser o adequado, o desempenho pode ser comprometido (LIPKIN; PERRYMORE, 2010)

Segundo os mesmos autores, a Geração $Y$ é levada pelos desafios, precisa estar sempre se desenvolvendo e crescendo profissionalmente. E em relação ao ambiente corporativo, é necessário que haja coletividade, flexibilidade, harmonia entre os colaboradores e uma boa interação entre a vida profissional e a pessoal.

Essa geração também se caracteriza por questionar as ordens emitidas e a falta de explicações sobre as mesmas (CRAMPTON; HODGE, 2009), o que pode implicar em riscos quanto à resistência ou falta de comprometimento com metas no longo prazo. Segundo Oliveira (2009), os profissionais dessa geração necessitam de orientação por parte de seus gestores, com um foco mais no diálogo e na negociação de expectativas. Fazer questionamentos é uma das características dessa geração, e por isso, é importante que os seus líderes sejam transparentes, ouçam e levem em consideração ao que é falado. Esses profissionais almejam respostas claras e diretas, com contínuo feedback.

Pela confiança dessa geração ser exacerbada, a maioria desses jovens acreditam ser capazes de realizar a maior parte das tarefas que lhes são atribuídas e de lidar com diferentes trabalhos e cargos, talvez melhor que o seu par da equipe, mesmo que ele tenha vinte anos a mais em experiência. Essa autoconfiança também reflete no desejo de ter mais responsabilidade, embora isso aconteça antes de darem conta de suas tarefas e responsabilidade atual. Quando um funcionário da Geração $Y$ entra em uma nova empresa, o seu desejo é receber uma promoção rápida, o que é pouco realista. Embora essas características possam incomodar sua equipe e todos os colaboradores em volta, essa vontade faz com que esses jovens sigam uma trilha para o sucesso. (LIPKIN; PERRYMORE, 2010)

A Geração Y nasceu em uma época em que já havia computadores. O, contato com a internet e websites veio desde cedo, e assim adquiriram uma intimidade com a tecnologia e suas inovações. Esses fatores contribuem 
positivamente para o desenvolvimento do profissional na organização, dado a grande habilidade com as novas tecnologias e ambientes de constante mudanças. (TULGAN, 2009).

A convivência de diferentes gerações no ambiente organizacional requer inovação e criatividade da área de gestão de pessoas. (SOARES, 2009).

\subsection{Gestão de pessoas}

Para Mósca, Cereja e Bastos (2014), a área de Gestão de Pessoas contempla um grupo de ações de uma pessoa ou mais, dentro de uma empresa, com a finalidade de auxiliar o trabalho tanto coletivo quanto individual, e visando atingir as metas e objetivos coletivos. A heterogeneidade do ambiente organizacional tem influência direta nas organizações, ofertando complexos desafios à área de Gestão de Pessoas.

Quando a estratégia de gestão de RH está integrada na organização, ela exerce importante papel na identificação dos problemas de recursos humanos da empresa e na criação de soluções. A estratégia é direcionada às ações e ao indivíduo. Atualmente as organizações conseguem atingir e manter sua eficácia com programas e atividades efetivas, realizadas pela área de gestão de pessoas (IVANCEVICH, 2008).

Os funcionários passaram a ser considerados ativos valiosos para as empresas, e não apenas recursos (CHIAVENATO, 2010). Complementando, segundo Pfeffer (1994), cada funcionário é único, em suas características, representando assim uma vantagem competitiva importante para as organizações.

As estratégicas de $\mathrm{RH}$ devem refletir claramente o objetivo organizacional. Hoje, com o reconhecimento da importância crucial das pessoas, a gestão de pessoas, em um número cada vez maior de organizações, tem-se tornado fundamental no desenvolvimento de planos estratégicos. Em resumo, a maioria das organizações veem a gestão de pessoas como uma área, onde pode-se extrair lucro, e não apenas como uma área de despesas. (IVANCEVICH, 2008).

Assim, a gestão de pessoas surgiu como uma solução para as demandas de excelência organizacional. A explosão de informações e o avanço da tecnologia desmistificou alguns conceitos como: fontes de recrutamento; novos métodos de seleção; treinamento e desenvolvimento com múltiplas facetas; planos de carreira não só originados na própria organização, mas também projetados pelas próprias pessoas; muitas possibilidades para avaliar 0 
desempenho e auto avaliação; benefícios crescentes e customizados para determinados grupamentos; exigência de novas competências e uma nova visão de liderança tendo, principalmente a cultura organizacional, como pano de fundo (DUTRA, 2016).

Para complementar, Arthur e Rosseau (1996) asseguram as práticas de gestão de pessoas são boas ferramentas para esculpir o comportamento dos funcionários. E consequentemente os transformam na principal vantagem competitiva da organização.

\subsubsection{Práticas de gestão de pessoas}

Para Mósca, Cereja e Bastos (2014), as práticas de Gestão de Pessoas podem ser caracterizadas como ferramentas estratégicas para atingir aos objetivos organizacionais.

Uma estratégia de gestão de pessoas bem formulada ajuda a agregar e a alocar os recursos da empresa em uma entidade única, com base nos pontos fortes e fracos internos, nas mudanças ambientais e nas ações antecipadas da concorrência. (IVANCEVICH, 2008). O autor ainda complementa, que as práticas de gestão de pessoas, garantem aos funcionários respeito, tratamento justo, recompensas pela competência, oportunidades de crescimento pessoal em um ambiente incentivador, treinamento e, consequentemente, desenvolvimento.

O sistema de gestão de pessoas busca práticas alinhadas, que impactam significativamente a rotatividade de funcionários, produtividade, resultados financeiros e corporativos. Contudo, é necessário implementá-las de forma consistente, pois isoladas e desarticuladas, tem capacidade limitada de gerar vantagem competitiva. Estudos sugerem que a escolha dessa combinação ideal de práticas é crucial para levar a melhores resultados organizacionais. (GIL, 2007; SCOTTI; DUTRA, 2016; CHIAVENATO 2010).

Segundo Posthuma et al (2013) as práticas de gestão de pessoas podem ser divididas em 9 categorias; Compensação e benefícios; Emprego e design de trabalho; Treinamento e desenvolvimento; Recrutamento e Seleção; Relações com funcionários; Comunicação; Gestão de Desempenho e Avaliação; Promoções; Turnover e retenção e gerenciamento da saída de funcionários. Já para Chiavenato (2010) a classificação é feita em 6 processos: agregar, aplicar, recompensar, desenvolver, manter pessoas e monitorar pessoas.

Oliveira (2010) pontua questões que são levadas em consideração na escolha de uma empresa pelos jovens da Geração Y. São elas: Crescimento de 
carreira, Desenvolvimento profissional, Ambiente de trabalho agradável, Bons salários e benefícios, Cursos e treinamentos.

Neste trabalho, serão descritas e conceituadas práticas, relacionadas às questões mencionadas pelo autor Oliveira (2010). No âmbito de Gestão de Pessoas, esses tópicos podem ser traduzidos para práticas, como: Treinamento e Desenvolvimento; Avaliação de Desempenho; Remuneração e Benefícios; Clima organizacional e qualidade de vida no trabalho; Plano de Carreira.

As práticas de treinamento e desenvolvimento são importantes para a retenção dos talentos internos, e, a seguir, serão destacados conceitos desse tema.

\subsubsection{Treinamento e desenvolvimento}

Para Chiavenato (2010), o treinamento é a forma de desenvolver as competências dos funcionários, tornando-os mais produtivos, inovadores e criativos. O autor complemente, que é uma maneira de aumentar o valor dos funcionários e atingir o objetivo comum.

Outro posicionamento sobre esse assunto é dado por Milkovich e Boudreau (2000), que consideram o treinamento um processo sistemático para promover a aquisição de habilidades, regras, conceitos ou atitudes que resultem em uma melhoria da adequação entre as características dos empregados e as exigências dos papéis funcionais. Em suma, eles acreditam que esse processo traz benefícios não só para a empresa, mas também às pessoas, à medida que eles adquirem habilidades, atitudes e conceitos novos.

Cada vez mais, os gastos com programas de T\&D (Treinamento e Desenvolvimento) tem sido encarados como investimentos estratégicos, seja a fim de condicionar pessoas à execução de tarefas, seja com o propósito de ampliar o nível de conhecimento pessoal. (ARAUJO; GARCIA, 2009). O investimento no desenvolvimento das pessoas significa investir na qualidade dos produtos e serviços ofertados, e consequentemente, atender melhor suas demandas. (TACHIZAWA; FERREIRA; FORTUNA, 2001)

Para iniciar-se qualquer plano de treinamento e desenvolvimento é necessário entender a necessidade e o desempenho previamente. A seguir será detalhado mais a respeito dessa prática. 


\subsubsection{Avaliação de desempenho}

Dessler (2003), declara que esta prática pode ser estabelecida como uma maneira de avaliar a ligação entre as obrigações de determinado funcionário e seu desempenho organizacional. Para tal ligação ocorrer corretamente, é necessário que o desempenho esperado seja pré-estabelecido junto ao gestor e durante o trajeto ocorra periódicos feedbacks, com o objetivo de auxiliar no desempenho e descartar falhas.

Já Chiavenato (2003) possui uma outra perspectiva sobre a prática de avaliação de desempenho, alegando ser um processo de atenuação de oscilações e busca por conformidade organizacional.

Para Lucena (1992), a sistematização da Avaliação de Desempenho visa apenas dotar a empresa de uma ferramenta gerencial ou de um processo mais bem estruturado para conduzir de forma mais eficaz a gestão do desempenho na busca da motivação, da qualidade, da produtividade e de resultados positivos de trabalho. A autora ainda complementa que não se trata apenas de saber se os objetivos foram alcançados, mas sim assegurar se foram atingidos e como serão atingidos. Isso requer a definição antecipada do desempenho desejado, a análise das possibilidades profissionais dos funcionários para desempenharem suas tarefas, desenvolver as habilidades necessárias, assim como reconhecer o seu trabalho e suas contribuições efetivas.

Definir os resultados esperados de cada empregado significa especificar as atribuições, metas, projetos, atividades, tarefas que compõem o seu campo de responsabilidade profissional. Mas é preciso também estabelecer padrões de desempenho, ou seja, o que é esperado, qual o nível de qualidade desejada e quais prazos para apresentar resultados. Para o processo de da Avaliação de Desempenho ocorrer de maneira correta é necessário um acompanhamento sistemático e periódico do desempenho individual e da equipe. (LUCENA, 1992).

Desta forma, pode-se entender que a Avaliação de Desempenho abrange todo o processo desde a identificação do desempenho, passando pela sua mensuração, até cada pessoa alcançar o potencial desejado à serviço da organização.

Uma razão que pode alterar o comportamento e desempenho dos funcionários é a remuneração e benefícios recebidos, que serão explicados a seguir 


\subsubsection{Remuneração e benefícios}

A remuneração e os benefícios dados por uma organização aos seus colaboradores merecem atenção. Os benefícios podem ser classificados como os itens indiretos da remuneração, como vale alimentação ou refeição, seguro de vida, assistência odontológica, etc. Já a remuneração é o salário pago aos funcionários da empresa, de acordo com seu cargo e suas tarefas. (MARRAS, 2002).

A remuneração direta está relacionada com as funções atribuídas a determinadas posições, suas responsabilidades e atividades rotineiras, assim, irá variar com base no desempenho de cada posição. Já a remuneração indireta, ou seja, os benefícios sociais são incentivos internos oferecidos com o objetivo de satisfazer às necessidades pessoais, proporcionando um ambiente mais harmonioso possível e produtivo para toda a organização. (ARAUJO; GARCIA, 2009). Os benefícios sociais podem ser classificados como legais mandatórios, legais opcionais, intrínsecos e flexíveis.

Os custos com os colaboradores precisam estar em linha com a receita e os preços práticos no mercado pelas empresas. Mas, por outro lado, há uma rivalidade entre as organizações com o objetivo de atrair e manter seus talentos, desenvolvendo uma pressão por benefícios diferenciados (MIKOVICH e BOUDREAU, 2000).

A aplicação dos benefícios sociais em cada empresa, dependerá dos seus objetivos e características próprias, baseados na sua complexidade, no seu quadro de funcionários e na necessidade de crescimento e desenvolvimento organizacional.

Outros fatores, além da remuneração e benefícios, importantes para reter e satisfazer os colaboradores internos são o clima da organização e qualidade de vida no ambiente de trabalho, que serão abordados a seguir.

\subsubsection{Clima organizacional e qualidade de vida no trabalho}

O clima organizacional se caracteriza como todo o ambiente interno da empresa, incluindo tudo que o compõem (CHIAVENATO, 2004). Tal ambiente está ligado diretamente ao nível de satisfação dos funcionários. Para Smaneoto e Binsfeld (2013), a produtividade e a qualidade de vida estão diretamente ligadas ao clima organizacional harmônico. 
Luz (1995) acredita que esse clima deve ser analisado através de uma pesquisa, que com o levantamento das necessidades, deficiências e expectativas dos colaboradores, possibilita uma movimentação por parte da organização para alterar os aspectos que foram identificados como críticos. Complementando, Ferreira (2013) identifica a pesquisa de clima como uma ferramenta estratégica para identificar o sentimento dos colaboradores a respeito do clima organizacional e para atingir melhorias no ambiente de trabalho.

Para Chiavenato (2003), a qualidade de vida no trabalho tornou-se um coeficiente de grande destaque nas empresas. Segundo o autor, ela está diretamente relacionada à potencialização do capital humano.

Os empregados passaram a querer trabalhar em lugares mais agradáveis, assim as empresas são desafiadas a investir no ambiente, tanto para atrair talentos quanto para melhorar a produtividade do trabalho. (GIL, 2007). Os programas de qualidade de vida focalizam temas como redução de conflitos, satisfação dos empregados e participação no trabalho. Representa, um estado final desejado que enfatize a importância de proporcionar oportunidades, a fim de que os empregados contribuam para suas funções e tenham mais satisfação no trabalho. (VECCHIO, 2009)

O clima organizacional e a qualidade de vida no trabalho contribuem para a retenção do profissional, e consequentemente a construção da carreira dos colaboradores, a seguir será detalhado mais sobre essa prática.

\subsubsection{Plano de carreira}

O conceito de carreira vem sofrendo grandes mudanças ao longo do tempo. Robbins (2005) aponta que poucas práticas apresentaram tantas mutações no tempo, quanto o papel da organização na carreira dos seus funcionários. Por esse motivo, o tema carreira é bastante discutido nas empresas e no mercado. Logo, abordar esse conceito e colocá-lo em prática, se tornou um grande desafio para a área de gestão de pessoas.

Hall e Moss (1998) apresenta quatro significados distintos que as pessoas atribuem ao termo carreira: como mobilidade vertical, independente da área ou profissão; carreira como profissão, independentemente da organização em que ela é exercida; carreia como sequência de empregos durante a vida, independente da direção; carreia como sequência de experiências relacionadas a funções ao longo da vida, não se limitando a funções profissionais. 
Mósca, Cereja e Bastos (2014) acreditam que a preocupação com os planos de carreira pelas empresas deva ser recorrente, pois esses promovem autonomia e independência aos profissionais. Afim de reter esses profissionais, os autores complementam que há a necessidade de promover ações que os reconheça, além de flexibilidade e interação. 


\section{Métodos e procedimentos de coleta e de análise de dados do estudo}

Neste capítulo será apresentada a metodologia da pesquisa usada para responder a seguinte questão: Quais são as práticas de Gestão de Pessoas mais valorizadas pela geração $Y$ no ambiente organizacional?

\subsection{Etapas de coleta de dados}

O estudo iniciou-se com o levantamento das informações sobre os aspectos valorizados pela Geração $Y$ no ambiente corporativo. Elegeu-se algumas práticas de gestão de pessoas que os profissionais da Geração $Y$ valorizam, são elas: Treinamento e Desenvolvimento, Avaliação de Desempenho, Remuneração e Benefícios, Clima Organizacional e Qualidade de vida no trabalho e Plano de Carreira.

Para a composição do questionário fez-se necessário uma pesquisa bibliográfica, a partir de livros e artigos científicos, que segundo Vergara (2000) é desenvolvida para conseguir extrair as informações iniciais sobre os aspectos ligados à temática do estudo.

O tipo de pesquisa que foi realizada nesse estudo, foi a descritiva, pois segundo Vergara (2000), busca a resolução de problemas por meio da análise, observação e descrição objetiva.

A autora complementa, que uma pesquisa pode ser caracterizada através dos seus meios e dos seus fins. No que tange a forma, foi realizada uma pesquisa de campo, além de uma pesquisa bibliográfica. Para a pesquisa bibliográfica, foi utilizado material didático sobre os temas abordados, além de artigos, e sites da internet.

\subsection{Fontes de informação selecionadas para coleta de dados no estudo}

O universo da pesquisa consistiu em pessoas de 19 a 38 anos, nascidos entre 1980 e 1999, segundo Oliveira (2010), cuja faixa etária corresponde à Geração Y. Jovens que residam no Rio de Janeiro e que trabalham ou já 
trabalharam em regime formal, pelo menos por dois anos, em alguma organização.

A amostra utilizada é por conveniência, também conhecida como não probabilística, que segundo Gil (2007), é de simples alcance ao observador e não possui qualquer fundamento estatístico ou matemático.

Foi usado como base Jesus (2015), Melo (2016) e Del Grande (2017) para a elaboração do questionário. Pois os mesmos realizaram pesquisas relacionadas ao tema do presente estudo, mas com distintas perspectivas.

\subsection{Procedimentos e instrumentos de coleta de dados utilizados no estudo}

Como instrumento de coleta, foi feito levantamento tipo survey com questionário online, que será detalhado a seguir.

Para mitigar a possibilidade de erro durante o preenchimento do questionário e coleta de dados, foi feito um pré-teste, com o objetivo de identificar as possíveis falhas na elaboração do questionário, possibilitando assim, uma maior precisão na coleta das respostas.

De acordo com Barçante e Castro (1999), é possível identificar, através de um teste, a nitidez das questões e a adequação do questionário aos objetivos estabelecidos. O presente questionário foi testado por 6 pessoas, antes de ser validado.

A disseminação do questionário virtual se deu através do compartilhamento do link por meio das redes sociais e via e-mail. Com o objetivo de atrair o maior número possível de respondentes, de acordo com o público alvo.

O questionário utilizado iniciou-se com perguntas filtros, para avaliar se 0 respondente corresponde ao público alvo e assim, manter na pesquisa, somente o perfil desejado. A primeira pergunta se referiu à idade do respondente, e caso estivesse fora da margem da Geração $Y$, o questionário se encerraria, agradecendo a participação. A próxima pergunta tinha como objetivo identificar o tempo de experiência profissional em regime formal do respondente, caso a resposta estivesse abaixo de dois anos, o questionário se encerraria. A terceira e última pergunta filtro, era em relação ao estado de moradia do respondente, caso não resida no estado do Rio de Janeiro, o questionário se encerraria.

$\mathrm{Na}$ segunda parte do questionário foram apresentadas questões sobre as cinco práticas de Gestão de Pessoas contidas no referencial teórico a fim de 
entender se os respondentes discordam totalmente, discordam parcialmente, nem discordo e nem concordo, concordo parcialmente e concordo totalmente. A terceira e última parte do questionário tinha como objetivo colocar em ordem de preferência as práticas de gestão de pessoas.

\subsection{Formas de tratamento e análise dos dados coletados para o estudo}

Segundo Vergara (2004), a análise dos dados pode ser feita de duas maneiras: qualitativa e/ou quantitativa. A primeira é realizada através da análise mais profunda das informações, enquanto a segunda é feita por meio de métodos estatísticos. $\mathrm{E}$ até mesmo utilizar as duas técnicas simultaneamente.

Nesse trabalho optou-se por utilizar as duas técnicas em conjunto. Foram gerados gráficos com as respostas, e ao mesmo tempo, ocorreu a análise das mesmas levando em consideração o referencial teórico do estudo.

\subsection{Limitações do estudo}

Esse estudo teve como objetivo compreender as práticas de gestão de pessoas mais valorizadas pela Geração Y, contudo, o trabalho possuiu algumas limitações que serão vistas a seguir.

A primeira, foi em relação ao não conhecimento de questões pessoais dos respondentes, e com isso, houve possibilidade de deturpação de algumas respostas. Outra limitação foi a barreira para esclarecer possíveis dúvidas durante o preenchimento, visto que o questionário é aplicado online. Mesmo o email sendo disponibilizado no início do questionário, a interação entre pesquisadora e respondente é comprometida.

Contudo, apesar de tais limitações, o estudo atendeu aos objetivos esperados, pois identificou quais práticas de gestão de pessoas os jovens da Geração $Y$ mais valorizam. 


\section{Apresentação e análise dos resultados}

\subsection{Descrição e análise dos resultados}

Este capítulo apresenta e discute os principais resultados alcançados, considerando o referencial teórico adotado.

Foi formulado um questionário fundamentando-se na Geração $Y$ e práticas relacionadas à Gestão de Pessoas, como: treinamento e desenvolvimento; avaliação de desempenho; remuneração e benefícios; clima organizacional e qualidade de vida no trabalho e plano de carreira.

Destaca-se, que o questionário foi iniciado por 417 pessoas, mas considerou-se apenas 326 respondentes como amostra, após a conclusão do questionário com filtros eliminatórios, relacionados com a delimitação do estudo.

\subsection{Descrição do perfil dos respondentes}

São residentes do estado do Rio de Janeiro os 326 respondentes, além de serem graduados e nascidos entre 1980 e 1999. Possuem, também, ao menos dois anos de experiência formal no mercado de trabalho, excluindo, portanto, estágios.

Verificou-se, em primeiro lugar, a data de nascimento dos respondentes e consequentemente sua idade, que variou entre 19 e 38 anos. Os resultados foram separados da seguinte forma: $54 \%$ dos interrogados têm entre 31 e 38 anos, 37\% entre 25 e 30 anos e, finalmente, 9\% entre 19 e 24 anos. Os dados estão demonstrados na Tabela 1.

Tabela 1: Idade dos respondentes.

\begin{tabular}{|lcc|}
\hline & Idade & \\
Ano de Nascimento/ldade & Respondentes & Percentual \\
$1980-1987$ (31 a 38 anos) & 177 & $54,4 \%$ \\
\hline $1988-1993$ (25 a 30 anos) & 120 & $36,8 \%$ \\
\hline $1994-1999$ (19 a 24 anos) & 29 & $8,8 \%$ \\
\hline Total & 326 & $100,0 \%$ \\
\hline
\end{tabular}

Fonte: Próprio autor (2018). 
A maioria dos pesquisados da pesquisa são do sexo masculino, com uma porcentagem de 52\%, conforme Tabela 2.

Tabela 2: Gêneros dos respondentes.

\begin{tabular}{|lcc|}
\hline & Sexo & \\
Gênero & Respondentes & Percentual \\
Feminino & 155 & $47,6 \%$ \\
\hline Masculino & 171 & $52,4 \%$ \\
\hline Total & 326 & $100,0 \%$ \\
\hline
\end{tabular}

Fonte: Próprio autor (2018).

No que se refere ao grau de escolaridade, existia uma pergunta filtro que encerrava o questionário caso o nível não fosse, pelo menos, a graduação completa. Havia a possibilidade de escolher a opção pós-graduação completa/cursando também. Percebeu-se que, $64 \%$ dos interrogados têm apenas a graduação completa, e 36\% cursando ou também já completaram alguma pós-graduação, como evidenciado na Tabela 3.

Tabela 3: Grau de escolaridade.

\begin{tabular}{|lcc|}
\hline \multicolumn{3}{c}{ Grau de escolaridade } \\
Formação & Respondentes & Percentual \\
Superior Completo & 208 & $63,8 \%$ \\
\hline Pós-graduação cursando/completo & 118 & $36,2 \%$ \\
\hline Total & 326 & $100,0 \%$ \\
\hline
\end{tabular}

Fonte: Próprio autor (2018).

O curso de graduação também foi um item questionado na pesquisa e o destaque foi a formação em Administração com 33\%. Enquanto 11\% responderam ter cursado Engenharia e a mesma porcentagem cursou Economia. Os outros $45 \%$ disponíveis foram divididos entre os cursos de Comunicação, Direito, Psicologia e outros. Essa última alternativa, acumulou um total de $22 \%$. Os respondentes citaram cursos como Relações Internacionais, Medicina e Arquitetura. Os resultados estão presentes na Tabela 4. 
Tabela 4: Curso de formação.

\begin{tabular}{|lcc|}
\hline \multicolumn{2}{c}{ Formação } & \\
\hline Curso & Respondentes & Percentual \\
Administração & 109 & $33,5 \%$ \\
\hline Engenharia & 37 & $11,5 \%$ \\
\hline Economia & 35 & $10,8 \%$ \\
\hline Comunicação Social & 31 & $9,6 \%$ \\
\hline Direito & 24 & $7,5 \%$ \\
\hline Psicologia & 19 & $5,7 \%$ \\
\hline Outro & 70 & $21,5 \%$ \\
\hline Total & 326 & $100,0 \%$ \\
\hline
\end{tabular}

Fonte: Próprio autor (2018).

\subsection{Características da Geração Y}

Para caracterizar os profissionais da Geração Y, inicialmente, foram questionados sobre qual tipo de empresa eles trabalharam ou trabalham.

As respostas mostraram que $92 \%$ trabalham/trabalharam em empresa privada, em torno de $6 \%$ em empresa pública, apenas $2 \%$ em ONGs e $1 \%$ em outros tipos de empresa, como por exemplo, escritório de advocacia. O resultado segue na Tabela 5.

Tabela 5: Tipos de empresa.

\begin{tabular}{|lcc|}
\hline \multicolumn{3}{c}{ Tipo de Empresa } \\
\hline Empresa & Respondentes & Percentual \\
Privada & 298 & $91,5 \%$ \\
\hline Pública & 21 & $6,3 \%$ \\
\hline ONG & 5 & $1,6 \%$ \\
\hline Outro & 2 & $0,6 \%$ \\
\hline Total & 326 & $100,0 \%$ \\
\hline
\end{tabular}

Fonte: Próprio autor (2018).

A seguir, foram questionados a quantidade de empresas que os jovens da Geração $Y$ já trabalharam formalmente, sem incluir estágio, o tempo na última empresa, descartando também estágio e se estão trabalhando ou não atualmente. Essas perguntas foram feitas com o objetivo de identificar mais afundo as características de comportamento desses profissionais dentro do mercado de trabalho para avaliar com mais precisão a valorização das práticas de Gestão de Pessoas por esses indivíduos.

Verificou-se que $69 \%$ dos respondentes trabalharam, no máximo, em 2 empresas, enquanto $31 \%$ trabalharam em mais de 3 empregos. 
Tabela 6: Quantidade de empresas em que já trabalhou.

\begin{tabular}{|lcc|}
\hline \multicolumn{3}{|c|}{ Quantas empresas já trabalhou } \\
\hline $1-2$ & Respondentes & Percentual \\
\hline $3-4$ & 226 & $69,4 \%$ \\
\hline 5 ou mais & 75 & $23,1 \%$ \\
\hline Total & 25 & $7,6 \%$ \\
\hline
\end{tabular}

Fonte: Próprio autor (2018).

No quesito tempo de permanência no último ou atual emprego, $13 \%$ dos pesquisados permaneceram menos de um ano na sua última experiência profissional, enquanto $48 \%$ ficaram de um até três ano na última empresa, $21,6 \%$ entre três e quatro anos e $17,6 \%$ dos respondentes ficaram cinco ou mais anos na sua última experiência profissional. Oliveira (2010) diz que os jovens da Geração $Y$ pensam mais a curto prazo. Tulgan (2009) complementa que esses profissionais não possuem muita paciência e quando entram em alguma empresa, tem uma expectativa de rápido crescimento. A pesquisa mostrou que $61 \%$ dos profissionais permanecem até 3 anos na empresa, destacando, assim, os autores.

Tabela 7: Duração da última/atual experiência profissional.

\begin{tabular}{|lcc|}
\hline \multicolumn{3}{|c|}{ Duração da última/atual experiência profissional } \\
\hline Tempo & Respondentes & Percentual \\
$0-1$ ano & 42 & $13,0 \%$ \\
\hline $1-3$ anos & 156 & $47,8 \%$ \\
\hline $3-4$ anos & 70 & $21,6 \%$ \\
\hline 5 ou mais anos & 57 & $17,6 \%$ \\
\hline Total & 326 & $100,0 \%$ \\
\hline
\end{tabular}

Fonte: Próprio autor (2018).

Identificou-se que $82 \%$ dos respondentes estavam trabalhando no período da pesquisa, enquanto 18\% não. Como mostra a Tabela 8. 
Tabela 8: Está trabalhando atualmente?

\begin{tabular}{|lcc|}
\hline & Está atualmente empregado? & \\
\hline Quantidade & Respondentes & Percentual \\
\hline Sim & 269 & $82,5 \%$ \\
\hline Não & 57 & $17,5 \%$ \\
\hline Total & 326 & $100,0 \%$ \\
\hline
\end{tabular}

Fonte: Próprio autor (2018).

\subsection{Geração Y e as práticas de gestão de pessoas}

A partir das respostas apresentadas na tabela 8, os pesquisados foram direcionados para duas perguntas distintas. Para aqueles que responderam que estão empregados atualmente, a pergunta seria a respeito dos motivos pelos quais sairia da sua empresa atual. Enquanto para aqueles que responderam que estão desempregados, a pergunta foi sobre os motivos de saída da sua última experiência profissional. Nas suas perguntas havia a opção de marcar múltiplas respostas. Os resultados estão expostos nas Tabelas 9 e 10.

Tabela 9: Por qual(is) motivo(s) você sairia de sua atual empresa?

\begin{tabular}{|lcc|}
\hline \multicolumn{3}{|c|}{ Por qual(is) motivo(s) você sairia da sua empresa atual? } \\
Quantidade & Respondentes & Percentual \\
Horário de trabalho & 31 & $12 \%$ \\
\hline Remuneração recebida & 137 & $51 \%$ \\
\hline Benefícios disponíveis & 98 & $36 \%$ \\
\hline Perspectiva de crescimento & 168 & $62 \%$ \\
\hline Plano de carreira estruturado & 112 & $42 \%$ \\
\hline Reconhecimento por um bom trabalho feito & 101 & $38 \%$ \\
\hline Feedback periódico & 79 & $29 \%$ \\
\hline Treinamentos para desenvolvimento profissional & 65 & $24 \%$ \\
\hline Relacionamento com colaboradores e gestor & 53 & $20 \%$ \\
\hline Ambiente de trabalho & 74 & $28 \%$ \\
\hline Desafios profissionais & 103 & $38 \%$ \\
\hline Outros & 0 & $0 \%$ \\
\hline Fon: Prop
\end{tabular}

Fonte: Próprio autor (2018). 
Tabela 10: Por qual(is) motivo(s) você saiu do seu último emprego?

\begin{tabular}{|lcc|}
\hline \multicolumn{3}{|c|}{ Por qual(is) motivo(s) você saiu da sua última empresa? } \\
Quantidade & Respondentes & Percentual \\
Horário de trabalho & 3 & $5 \%$ \\
\hline Remuneração recebida & 16 & $28 \%$ \\
\hline Benefícios disponíveis & 10 & $17 \%$ \\
\hline Perspectiva de crescimento & 26 & $45 \%$ \\
\hline Plano de carreira estruturado & 13 & $23 \%$ \\
\hline Reconhecimento por um bom trabalho feito & 21 & $37 \%$ \\
\hline Feedback periódico & 5 & $9 \%$ \\
\hline Treinamentos para desenvolvimento profissional & 8 & $14 \%$ \\
\hline Relacionamento com colaboradores e gestor & 15 & $26 \%$ \\
\hline Ambiente de trabalho & 6 & $10 \%$ \\
\hline Desafios profissionais & 10 & $17 \%$ \\
\hline Outros & 7 & $12 \%$ \\
\hline
\end{tabular}

Fonte: Próprio autor (2018).

Nota-se que, mais da metade dos respondentes que estão empregados, sairiam de suas empresas atuais se a mesma não possuísse perspectiva de crescimento (62\%), por conta da remuneração recebida (51\%), um plano de carreira estruturado (42\%), reconhecimento do trabalho feito e novos desafios profissionais, ambos com $38 \%$.

Para os pesquisados que estão desempregados, as respostas foram similares. A maior porcentagem de respostas deu-se, também, para a perspectiva de crescimento, com 45\%. Em segundo lugar, seguindo o padrão da resposta anterior, a remuneração recebida (28\%), na terceira posição a questão do relacionamento com colaboradores e gestor (26\%), seguido por um plano de carreira estruturado, com $23 \%$.

Observando, então, uma conformidade nas respostas, essencialmente em relação à perspectiva de crescimento, que liderou as respostas em ambas as perguntas, tanto para os respondentes empregados, quanto para os desempregados. Tal necessidade de perspectiva de carreia, é explicada por Alsop (2008). Para o autor, os profissionais dessa geração almejam um crescimento rápido. Lipkin e Perrymore (2010) também discorrem sobre essa questão e entendem que a Geração $Y$ é movida pelos desafios, e precisa estar sempre em crescimento profissional.

O motivo destacado na pesquisa, foi em relação a remuneração recebida, o mesmo atingiu o segundo lugar, em ambas as perguntas. Lipkin e Perrymore (2010) apontam que o que motiva esses profissionais é o fator financeiro, mas não exclusivamente. 
O relacionamento interpessoal no ambiente de trabalho, foi um dos destaques de motivo de saída do último trabalho na pesquisa. E esse fator também é destacado pelos autores, como forma de motivação dos funcionários.

Com o objetivo de avaliar agora especificamente, as práticas de Gestão de Pessoas, foram produzidos dez pareceres a respeito das seis práticas abordadas no referencial teórico. Para aprimorar as análises, com base em Del Grande (2017), foram compiladas as respostas "concordo totalmente" e "concordo parcialmente" como positiva e, consequentemente, as respostas "discordo parcialmente" e "discordo totalmente" como negativa.

Considerando a prática de treinamento e desenvolvimento, conforme apresentado na Tabela 11, 96\% dos respondentes consideram importante que tenham treinamentos em suas empresas para desenvolvê-los. E 98\% dos mesmos, julgam que um dos pontos responsáveis pelo sucesso da empresa é o desenvolvimento dos seus funcionários. Esses resultados indicam concordância com a afirmação de Oliveira (2010), que defende que a Geração Y está constantemente procurando adquirir novos conhecimentos. E segundo Araújo e Garcia (2009), as empresas passaram a encarar a prática de treinamento e desenvolvimento como investimentos estratégicos respaldando essa impressão positiva da Geração Y, que o desenvolvimento dos funcionários é um ponto importante para o sucesso da empresa.

Tabela 11: Treinamento e desenvolvimento.

\begin{tabular}{|lcc|}
\hline \multicolumn{1}{|c|}{ Treinamento e Desenvolvimento } & Positiva & Negativa \\
\hline $\begin{array}{l}\text { Pergunta } \\
\text { Considero importante a empresa me desenvolver } \\
\text { através de treinamentos }\end{array}$ & $96 \%$ & $4 \%$ \\
\hline $\begin{array}{l}\text { Acredito que o desenvolvimento dos funcionários } \\
\text { seja um dos pontos responsáveis pelo sucesso da } \\
\text { empresa }\end{array}$ & $98 \%$ & $2 \%$ \\
\hline
\end{tabular}

Fonte: Próprio autor (2018).

No que se refere à avaliação de desempenho, os resultados são apresentados na Tabela 12. Para 99\% dos pesquisados é importante receber feedback do seu gestor, enquanto 92\% consideram importante 0 reconhecimento por um bom trabalho realizado. Esses fatos podem ser compreendidos de acordo com Oliveira (2010) que, afirma que os profissionais da Geração Y necessitam de um constante diálogo, respostas claras e diretas e feedback por parte de seus gestores. Os autores Lipkin e Perrymore (2010) 
afirmam que esses jovens desejam reconhecimento no desempenho de suas tarefas.

Tabela 12: Avaliação de desempenho.

\begin{tabular}{|lcc|}
\hline \multicolumn{1}{|c|}{ Avaliação de Desempenho } & Positiva \\
Pergunta & $\begin{array}{c}\text { Negativa } \\
\text { Entendo como importante o feedback do gestor }\end{array}$ & $1 \%$ \\
\hline $\begin{array}{l}\text { Considero importante ter o reconhecimento } \\
\text { constante pelo meu trabalho. }\end{array}$ & $92 \%$ & $8 \%$ \\
\hline
\end{tabular}

Fonte: Próprio autor (2018).

Em relação as práticas de remuneração e benefícios, os dados extraídos da pesquisa estão apresentados na Tabela 13. Observou-se que $98 \%$ dos respondentes acreditam que o salário seja um fator importante na hora de escolher onde trabalhar, e $85 \%$ dos respondentes procuram empresas que forneçam um bom pacote de benefícios, como vale refeição, ginástica, gasolina, estacionamento, etc.

O que respalda esses números é a indicação feita por Lipkin e Perrymore (2010), que caso a empresa não ofereça benefícios e remuneração adequados com suas responsabilidades e tarefas, a produtividade desses jovens da Geração Y pode ser comprometida.

Tabela 13: Remuneração e benefícios.

\begin{tabular}{|lcc|}
\hline \multicolumn{1}{|c|}{ Remuneração e Benefícios } & Negativa \\
\hline $\begin{array}{l}\text { Pergunta } \\
\begin{array}{l}\text { Considero salário um fator importante na decisão } \\
\text { de onde trabalhar }\end{array}\end{array}$ & $\begin{array}{c}\text { Positiva } \\
98 \%\end{array}$ & $2 \%$ \\
\hline $\begin{array}{l}\text { Procuro sempre empresas que ofereçam bons } \\
\text { benefícios (vale refeição, ginástica, gasolina, } \\
\text { estacionamento, etc..) }\end{array}$ & $85 \%$ & $15 \%$ \\
\hline Fonte: Próprio autor (2018). & &
\end{tabular}

As práticas relacionadas ao clima organizacional e qualidade de vida no trabalho foram agrupadas, e cada pergunta correspondeu à uma prática diferente. No que se refere o clima organizacional, 99\% dos pesquisados creem que um bom clima organizacional pode impactar tanto no desempenho individual quanto no resultado geral de uma empresa. E no âmbito de qualidade de vida no trabalho, a pesquisa identificou que $96 \%$ consideram importante ter estabilidade e equilíbrio entre a vida pessoal e profissional, como férias, carga horária flexível e home office, por exemplo. 
Os achados da pesquisa podem ser compreendidos em conformidade com Alsop (2008), que indica que os profissionais Millennials desejam desenvolver suas competências em ambiente de trabalho mais flexível. Lipkin e Perrymore (2010) também fornecem informações que permitem uma melhor compreensão das respostas visto que apontam que esses jovens buscam um ambiente corporativo harmonioso que permita um equilíbrio entre a vida pessoal e a profissional.

Tabela 14: Clima organizacional e qualidade de vida no trabalho.

\begin{tabular}{|lcc|}
\hline \multicolumn{3}{|c|}{ Clima Organizacional e Qualidade de Vida no Trabalho } \\
\hline $\begin{array}{l}\text { Pergunta } \\
\text { Considero importante ter estabilidade e equilíbrio }\end{array}$ & Positiva & Negativa \\
entre vida pessoal e profissional, como férias, & $96 \%$ & $4 \%$ \\
carga horária flexível e home office. & & $1 \%$ \\
\hline $\begin{array}{l}\text { Acredito que um bom clima organizacional impacta } \\
\text { no meu desempenho e nos resultados da empresa. }\end{array}$ & $99 \%$ & \\
\hline
\end{tabular}

Fonte: Próprio autor (2018).

Nessa etapa com afirmações sobre cada prática de gestão de pessoas, a última analisada foi o plano de carreira dos colaboradores. Mósca, Cereja e Bastos (2014) declaram que é de responsabilidade das organizações promover programas de carreira que proporcionem aos profissionais independência e autonomia durante seu trabalho.

A pesquisa também indicou a importância desses programas, com 89\% dos pesquisados afirmando preferirem uma empresa que tenha um plano de carreira estruturado e $91 \%$ dizem que sairiam de suas empresas atuais, caso não promovam oportunidades de crescimento.

Esses resultados podem ser compreendidos de acordo com Lipkin e Perrymore (2010), que alegam que logo quando um funcionário da Geração Y entra em uma nova empresa, almeja um rápido crescimento, por terem uma confiança exacerbada. E, caso esse crescimento não aconteça, esses profissionais podem se desmotivar. 
Tabela 15: Plano de carreira.

\begin{tabular}{|lcc|}
\hline \multicolumn{1}{c}{ Plano de Carreira } & Positiva & Negativa \\
\hline $\begin{array}{l}\text { Pergunta } \\
\begin{array}{l}\text { Prefiro procurar uma empresa que tenha um plano } \\
\text { de carreira estruturado }\end{array}\end{array}$ & $89 \%$ & $11 \%$ \\
\hline $\begin{array}{l}\text { Sairia da minha atual empresa por não haver } \\
\text { oportunidade de crescimento }\end{array}$ & $91 \%$ & $9 \%$ \\
\hline
\end{tabular}

Fonte: Próprio autor (2018).

$\mathrm{Na}$ terceira e última etapa do questionário, foi solicitado ao respondente que colocasse em ordem de preferência, de 1 a 6 , sendo a número 1 a mais importante e 6, menos importante, seis afirmações sobre cada uma das práticas de Gestão de Pessoas. Os resultados seguem na Tabela 16.

Tabela 16: Práticas de gestão de pessoas.

\begin{tabular}{|l|c|c|c|c|c|c|}
\hline $\begin{array}{l}\text { Resposta } \\
\text { Treinamento e desenvolvimento para } \\
\text { os funcionários }\end{array}$ & $7 \%$ & $2^{\circ}$ & $3^{\circ}$ & $4^{\circ}$ & $5^{\circ}$ & $6^{\circ}$ \\
\hline $\begin{array}{l}\text { Qualidade de vida pessoal e } \\
\text { profissional }\end{array}$ & $29 \%$ & $22 \%$ & $28 \%$ & $9 \%$ & $9 \%$ & $3 \%$ \\
\hline $\begin{array}{l}\text { Oportunidade de crescimento } \\
\text { profissional }\end{array}$ & $34 \%$ & $16 \%$ & $19 \%$ & $15 \%$ & $12 \%$ & $4 \%$ \\
\hline Remuneração e benefícios atrativos & $21 \%$ & $27 \%$ & $14 \%$ & $24 \%$ & $7 \%$ & $7 \%$ \\
\hline Ambiente de trabalho agradável & $7 \%$ & $23 \%$ & $15 \%$ & $32 \%$ & $14 \%$ & $9 \%$ \\
\hline $\begin{array}{l}\text { Avaliação periódica de desempenho } \\
\text { das atividades desempenhadas }\end{array}$ & $2 \%$ & $6 \%$ & $10 \%$ & $4 \%$ & $27 \%$ & $51 \%$ \\
\hline $\begin{array}{l}\text { Fonte: Próprio autor (2018). } \\
\text { Fonter }\end{array}$ & & & & &
\end{tabular}

Conforme ressalta a Tabela $16,34 \%$ dos pesquisados relacionaram a oportunidade de crescimento profissional, ou seja, o plano de carreira como a prática de Gestão de Pessoas mais prestigiada. A prática de remuneração e benefícios, apesar de não ser um tema abordado com profundidade na bibliografia da Geração Y, foi classificada com 27\%, como a segunda prática mais importante pelos profissionais dessa geração. A terceira prática, considerada por $28 \%$ dos respondentes, foi a qualidade de vida, possibilidade de equilibrar vida pessoal e profissional. O clima organizacional, foi a quarta prática elegível pelos pesquisadores com 32\%. Em penúltimo lugar, apareceu o treinamento e desenvolvimento, com 30\% dos respondentes. Enfim, a prática menos valorizada pela Geração $Y$, foi a avaliação de desempenho, por mais da metade dos respondentes. 


\section{Conclusões e recomendações para novos estudos}

\subsection{Conclusão}

O objetivo do presente estudo foi o de identificar as práticas relacionadas à Gestão de Pessoas mais valorizadas pelos profissionais da Geração $Y$ no ambiente corporativo. Para atingi-lo, foi realizada pesquisa bibliográfica, que apresentou conceitos referente à Geração $\mathrm{Y}$, aspectos comportamentais relacionados ao ambiente corporativo e características comportamentais dos $\mathrm{Y}$. Além de uma pesquisa de campo com o público alvo. Foram descritos conceitos de práticas de Gestão de Pessoas.

No que diz respeito a pesquisa de campo, foi elaborado e aplicado a uma amostra final de 326 respondentes. Apesar da diferença de cursos, sexos opostos e idades distintas, houve um padrão nas respostas obtidas. Os comportamentos atribuídos à Geração $Y$ estão em linha com a pesquisa bibliográfica feita previamente.

A Tabela 17, a seguir, demostra quais as práticas de Gestão de Pessoas são mais valorizadas pelos profissionais da Geração $Y$, por ordem de importância.

Tabela 17: Ordenação das práticas de gestão de pessoas.

\begin{tabular}{|c|l|}
\hline Ordem & \multicolumn{2}{c|}{ Práticas de Gestão de Pessoas } \\
\hline $1^{\circ}$ & Oportunidade de crescimento profissional \\
\hline $2^{\circ}$ & Remuneração e benefícios atrativos \\
\hline $3^{\circ}$ & Qualidade de vida pessoal e profissional \\
\hline $4^{\circ}$ & Ambiente de trabalho agradável \\
\hline $5^{\circ}$ & Treinamento e desenvolvimento para os funcionários \\
\hline $6^{\circ}$ & Avaliação periódica de desempenho das atividades desempenhadas \\
\hline
\end{tabular}

Fonte: Próprio autor (2018).

Conclui-se nesse estudo, que oportunidade de crescimento, também chamada de plano de carreira, foi a prática de Gestão de Pessoas mais valorizada pelos respondentes da Geração Y. Esses jovens possuem a necessidade de crescimento acelerado e buscam oportunidades que facilitem essa desejada ascensão (OLIVEIRA, 2010). Os profissionais dessa geração se 
interessam por empresas que tenham um plano de carreira acelerado, pois almejam uma acelerada escalada profissional. (LIPKIN E PERRYMORE, 2010).

Em segundo lugar, encontra-se Remuneração e benefícios atrativos, pois estas, assim como outras formas de premiações, são práticas valorizadas por eles (CALLIARI e MOTTA, 2012). Qualidade de vida profissional e pessoal apareceu em terceiro lugar na ordem de preferência. Uma explicação é dada por Lipkin e Perrymore (2010), que alegam que a Geração $Y$ deseja trabalhar em uma organização em que haja um bom equilíbrio e interação entre a vida pessoal e profissional.

O Clima organizacional apareceu em quarto lugar na pesquisa realizada. Os profissionais da Geração $Y$ valorizam a harmonia em suas relações interpessoais e um ambiente de trabalho agradável (LEMOS at al, 2012).

Treinamento e desenvolvimento aparecem em quinto lugar demonstrando não ser um fator tão relevante para os profissionais da Geração Y. Esses jovens são caracterizados por uma confiança exacerbada, em comparação às gerações anteriores. Acreditam que são capazes de realizar a maior parte das tarefas e lidar com diferentes trabalhos e cargos (LIPKIN; PERRYMORE, 2010). Não percebe a necessidade de serem treinados com frequência, pois acreditam já possuírem as competências necessárias e acreditam na possibilidade de aprenderem sozinhos, utilizando os recursos da internet.

A prática menos valorizada foi a avaliação de desempenho. Como forma de interpretar esse dado, Oliveira (2010) aponta que a Geração Y, apesar de ter necessidade de feedback periódico, tende a ter dificuldade em aceitá-los (CALLIARI e MOTTA, 2012). Isso pode ser explicado, por terem sido mimados pelos seus pais, como forma de compensar a presença no mercado de trabalho de ambos - pai e mãe - desde muito cedo.

Pode-se entender, que é importante que as áreas de Gestão de Pessoas tenham sua atenção voltada para as práticas apresentadas nesse estudo, para atrair e reter os profissionais da Geração Y. O foco deve ser, principalmente, quanto a oportunidade de crescimento, remuneração e benefícios e qualidade de vida no trabalho, que foram as três práticas identificadas como as mais valorizadas nessa pesquisa. Os jovens dessa geração se preocupam em fazer carreira, ganhar salário e benefícios compatíveis com suas tarefas e atribuições, além de ter um equilíbrio entre a vida pessoal e a profissional. Caso a organização em que estejam não consiga atender esses principais objetivos, é possível que se inicie a busca por outra oportunidade de trabalho, que atenda aos seus desejos e ambições. 
A Geração Y é exigente e não se preocupa em trocar de emprego para se adequar aos seus objetivos de vida. Por isso, é preciso que as organizações estejam atentas a esse perfil de jovens.

\subsection{Sugestões e recomendações para novos estudos}

O presente estudo trouxe contribuições para o entendimento da Geração Y no ambiente coorporativo, bem como para a avaliação da percepção desses profissionais frente às práticas tradicionalmente desenvolvidas pela área de Gestão de Pessoas.

Como esse estudo foi realizado com uma amostra por conveniência composta por residentes do estado do Rio de Janeiro, é possível que os dados não representem de forma significativa a Geração $Y$ como um todo, não só devido ao tamanho da amostra, mas também por considerar somente moradores de uma localidade. Sugere-se que a pesquisa seja aplicada para outras regiões com uma amostra maior para comparar os resultados obtidos com o presente estudo.

Outra sugestão é a realização de entrevistas com os membros dessa geração para entender, de forma mais aprofundada, como eles se comportam no ambiente organizacional. Também é válido traçar o perfil dessa geração considerando as classes sociais das quais fazem parte, para entender se este item interfere nas práticas de Gestão de Pessoas valorizadas. Além disso, recomenda-se entrevistar profissionais de Gestão de Pessoas para verificar o que eles identificam nos jovens da Geração $Y$ e quais práticas estão utilizando para captá-los e retê-los.

Por fim, sugere-se que estudos semelhantes sejam feitos usando como base outras gerações, principalmente a Geração Z, que será a mais nova entrante no mercado de trabalho. 
ALSOP, R. The trophy kids grow up: how the millennial generation is shaking up the workplace. 1. ed. San Francisco: Jossey-Bass, 2008.

ARTHUR, M., \& ROUSSEAU, D. (1996). A new career lexicon for the 21st century. The Academy of Management Executive, 10(4),28-39.

BARCANTE, L. C.; CASTRO, G. C. Ouvindo a voz do cliente interno: transforme seu funcionario num parceiro. Rio de Janeiro: Qualitymark, 1999. 97p.

CALLIARI, M.; MOTA, A. Código Y: decifrando a geração que está mudando o país. São Paulo: Évora, 2012.

CAVAZOTTE, F. S. C. N.; LEMOS, A. H. C.; VIANA, M. D. A. Novas Gerações no mercado de trabalho: expectativas renovadas ou antigos ideais? Caderno EBAPE.BR, Rio de Janeiro, v. 10, n. 1, p. 162-180, mar. 2012.

CHIAVENATO, I. Recursos humanos: o capital humano das organizações. 8. ed. São Paulo: Atlas, 2004.

- Gestão de pessoas: o novo papel dos recursos humanos nas organizações. 3. ed. Rio de Janeiro: Elsevier, 2010.

CRAMPTON, S. M.; HODGE, J. W. Generation Y: unchartered territory. Journal of Business e Economics Research, v. 7, n. 4, p. 1-6, abr. 2009.

DESSLER, G. Administração de recursos humanos. São Paulo: Prentice Hall, 2003.

DUTRA, J. S. Gestão de pessoas: modelo, processos, tendências e perspectivas. São Paulo: Atlas, 2016.

FERREIRA, P. I. Clima Organizacional e Qualidade de Vida no Trabalho. Rio de Janeiro: LTC, 2013.

FISCHER, A. L.; DUTRA, J. S.; AMORIM, W. A. C. Gestão de pessoas: práticas modernas e transformação nas organizações. São Paulo: Atlas, 2010.

DEL GRANDE, S. M. T. Geração Y: As práticas de Gestão de Pessoas mais valorizadas no mercado de trabalho. 2017. p. Trabalho de Conclusão (Graduação em Administração) - Departamento de Administração: Pontifícia Universidade Católica do Rio de Janeiro.

GIL, A. C. Gestão de Pessoas: enfoque nos papéis profissionais. 1. ed. São Paulo: Atlas, 2007.

2007.

Métodos e técnicas de pesquisa social. 5. ed. São Paulo: Atlas,

GLASS, A. Understanding generational differences for competitive success. Industrial e Commercial Training, v. 39, n. 2, p. 98-103, 2007.

HALL, D.T.; MOSS, J.E. The new protean career contract: helping organizations and employees adapt. Organizational dynamics, v.26, n.3, p.22-36, 1998. 
IVANCEVICH, J. M. Gestão de Recursos Humanos. 10 ed. São Paulo, Mcgraw Hill, 2008.

JESUS, M. As práticas de gestão de pessoas mais valorizadas pela geração Y. 2015. 55 p. Trabalho de Conclusão (Graduação em Administração) Departamento de Administração: Pontifícia Universidade Católica do Rio de Janeiro.

LAB SSJ. Geração Y: perspectivas sobre o ambiente multigeracional. São Paulo/Rio de Janeiro: Pocket Learning, 2010.

LEMOS, A. H. C.; CAVAZOTTE, F. S. C. N.; VIANA, M. D. A. Os jovens e o trabalho: valores, escolhas e expectativas. In: BARBOSA, L. Juventudes e gerações no Brasil contemporâneo. Porto Alegre: Sulina, 2012. p. 295-318.

LIPKIN, N.; PERRYMORE, A. A geração Y no trabalho: como lidar com a força de trabalho que influenciará definitivamente a cultura da sua empresa. Tradução de Bruno Alexandre. Rio de Janeiro: Elsevier, 2010.

LOUGHLIN, C.; BARLING, J. Young worker's work values, atitudes, and behaviours, v. 74, m. 4, 2010

LUCENA, M. D. S. Avaliação de Desempenho. São Paulo: Atlas, 1992.

LUZ, R. S. Clima Organizacional. Rio de Janeiro: Qualitymark, 1995.

Gestão do clima organizacional. Rio de Janeiro: Qualitymark, 2003.

MARRAS, J. P. Administração da remuneração. São Paulo: Pioneira Thomson Learning, 2002.

MELO, G. B. As práticas de gestão de pessoas mais valorizadas pela geração Y na escolha por oportunidades de estágio. 2016. 59 p. Trabalho de Conclusão de Curso (Graduação em Administração) - Departamento de Administração: Pontifícia Universidade Católica do Rio de Janeiro.

MELO, G. R.; LEMOS, A. H. C. Construção de Uma Carreira Bem Sucedida: O que querem as mulheres da geração $Y$ ? 2010. Trabalho de Conclusão de Curso (Graduação em Administração) - Departamento de Administração: Pontifícia Universidade Católica do Rio de Janeiro.

MILKOVICH, G. T.; BOUDREAU, J. W. Administração de recursos humanos. 1. ed. São Paulo: Atlas, 2000.

MÓSCA, H. M. B.; CEREJA, J. R.; BASTOS, S. A. P. Gestão de pessoas nas organizações contemporâneas. 1. ed. Rio de Janeiro: LTC, 2014.

MUNRO, R. C. Mentoring Needs and Expectations of Genaration-Y. Human Resources Practitioners: Preparing the Next Wave of Strategic Business Partners. Journal of Management Research, v.1, n.2, 2009.

OLIVEIRA, S. Geração Y: era das conexões - tempo dos relacionamentos. São Paulo: Clube dos Autores, 2009.

Geração Y: o nascimento de uma nova versão de líderes. São Paulo: Integrare, 2010.

PFEFFER, J. Vantagem competitiva através de pessoas. São Paulo: Makron Books, 1994.

POSTHUMA et al. A High Performance Work Practices Taxonomy: Integrating the Literature and Directing Future Research, v. 39, n.5, 2013 ROBBINS, S. P. Comportamento Organizacional. 9. Ed. São Paulo: Prentice Hall, 2005. 
SÁ, P. F.; LEMOS, A. H. C.; CAVAZOTTE, F. S. C. N. Expectativas de carreira na contemporaneidade: o que querem os jovens profissionais? Revista ADM.MADE, v. 18, n. 2, p. 8-27, 2014.

SMANEOTO, C.; BINSFELD, L. Retenção de talentos em organizações no ramo de informática. DESENVOLVE: Revista de Gestão do Unilasalle, Canoas, v. 2, n. 1, p. 157-170, abr. 2013.

SMOLA, K. W.; SUTTON, C. D. Generational differences: revisiting generational work values for the new millennium. Journal of Organizational Behavior, v. 23, p. 363-382, 2002.

SOARES, A. C. Novas tecnologias e as mudanças comportamentais e organizacionais. Administradores, 18 jul. 2009. Disponível em: <http://www.administradores.com.br/informe-se/producao academica/novas tecnologias-e-as-mudancas-comportamentais-e-organizacionais/2001/>. Acesso em: 14 de setembro de 2018.

STRAUSS, W.; HOWE, N.; Generations: the History os America's Future, 1584 to 2069. William Morrow and Company Inc., New York, NY. 1991

TACHIZAWA, T.; FERREIRA, V. C. P.; FORTUNA, A. A. N. Gestão Com Pessoas: uma Abordagem Aplicada às Estratégias de Negócios. São Paulo: FGV, 2001

TULGAN, B. Not everyone gets a trophy: how to manage generation Y. San Francisco: Jossey-Bass, 2009.

VECCHIO, R. P. Comportamento Organizacional. São Paulo: Cengage, 2009.

VELOSO, E. F. R.; DUTRA, J. S.; NAKATA, L. E. Percepções sobre carreiras inteligentes: diferenças das gerações $X, Y$ e baby boomers. Anais do Encontro Nacional de Programas de Pós-Graduação em Administração. Rio de Janeiro: ANPAD, 2008.

VERGARA, S. C. Projetos e relatórios de pesquisa em administração. São Paulo: Atlas, 2000.

WONG, M. et al. Generational differences in personality and motivation. Do they exist and what are the implications for the workplace? Journal of Managerial Psychology, v. 23, n. 8, p. 878-890, 2008. 


\section{Apêndice 1}

Olá, me chamo Luiza Martin e estou cursando o último período de Administração na Pontifícia Universidade Católica do Rio de Janeiro. Peço ajuda na conclusão do meu TCC, respondendo esse questionário, que é sobre a Geração $Y$ e as práticas de Gestão de Pessoas.

A pesquisa é destinada a jovens que nasceram entre os anos de 1980 e 1999, moradores do Rio de Janeiro, graduados e que já tenham pelo menos dois anos de experiência formal no mercado de trabalho

Se puderem compartilhar com os amigos o questionário, me ajudaria bastante. É bem fácil e rápido para preencher. O prazo final para responderem é até o dia 20 de Outubro e caso tenham alguma dúvida, por favor, entrem em contato comigo através do e-mail: luizademellomartin@gmail.com

Muito obrigada!

\section{Primeira parte}

1. Qual o ano que você nasceu?

-1980-1987

$\cdot 1988-1993$

$\cdot 1994-1999$

- Outro:

(Caso o respondente selecione outro, ele será direcionado para um agradecimento final e a pesquisa se encerrará).

2. Gênero?

- Feminino

- Masculino

- Outro

3. Você é morador (a) do estado do Rio de Janeiro?

- Sim

- Não 
(Caso o respondente selecione Não, ele será direcionado para um agradecimento final e a pesquisa se encerrará)

4. Qual seu grau de escolaridade?

- Ensino Fundamental

- Ensino Médio

- Ensino Superior Cursando

- Ensino Superior Completo

-Pós-graduação cursando ou completo

A próxima pergunta será exibida se selecionar superior completo ou Pósgraduação cursando ou completo.

5. Qual foi seu curso acadêmico?

- Administração

- Engenharia

- Economia

- Direito

- Psicologia

- Comunicação Social

- Outros:

Responder as próximas perguntas com base em experiências de emprego, descartando estágios.

6. Você já trabalhou com carteira assinada por pelo menos 2 anos?

- Sim

• Não

(Caso o respondente selecione Não, ele será direcionado para um agradecimento final e a pesquisa se encerrará)

7. Em qual empresa você trabalhou/trabalha?

- Pública

- Privada

- ONG

- Outro: 
8. Quanto tempo durou sua última/atual experiência profissional, não incluindo estágio?

-ano

-1-3 anos

-3-4 anos

- 5 ou mais anos

9. Já trabalhou em quantas empresas, descartando as passagens de estágio?

- De 1 a 2

- De 3 a 4

- 5 ou mais

10. Qual seu tempo total de experiência profissional, sem incluir estágios?

- De 2 a 4 anos

- De 5 a 7 anos

- De 8 a 10 anos

- De 11 a 14 anos

-15 anos ou mais

11. Você está empregado atualmente, sem incluir estágio?

- Sim

-Não

(Essa pergunta aparece se o Sim for selecionado)

12. Se sim, quais os motivos te levariam a sair da sua empresa atual, pode selecionar quantos itens achar necessário:

- Horário de trabalho

- Remuneração recebida

- Benefícios disponíveis

- Perspectiva de crescimento

- Plano de carreira estruturado

- Reconhecimento por um bom trabalho feito

- Feedback periódico entre gestor e colaborador

- Treinamentos para desenvolvimento profissional

- Relacionamento com colaboradores e gestor

- Ambiente de trabalho 
- Desafios profissionais

- Outros:

(Essa pergunta aparece se o Não for selecionado)

13. Se não, quais os motivos te levaram a sair da sua última empresa, pode selecionar quantos itens achar necessário:

- Horário de trabalho

- Remuneração recebida

-Benefícios disponíveis

- Perspectiva de crescimento

- Plano de carreira estruturado

- Reconhecimento por um bom trabalho feito

- Feedback periódico entre gestor e colaborador

- Treinamentos para desenvolvimento profissional

- Relacionamento com colaboradores e gestor

- Ambiente de trabalho

- Desafios profissionais

- Outros: 


\section{Segunda parte}

Baseado na sua experiência atual e/ou anterior, marque se você concorda totalmente, concorda parcialmente, nem concorda e nem discorda, discorda parcialmente ou se discorda totalmente.

\begin{tabular}{|c|c|c|c|c|}
\hline & $\begin{array}{l}\text { Concordo } \\
\text { totalmente }\end{array}$ & $\begin{array}{c}\text { Concordo } \\
\text { parcialmente }\end{array}$ & $\begin{array}{c}\text { Discordo } \\
\text { parcialmente }\end{array}$ & $\begin{array}{l}\text { Discordo } \\
\text { totalmente }\end{array}$ \\
\hline \multicolumn{5}{|l|}{$\begin{array}{c}\text { Considero importante a } \\
\text { empresa me } \\
\text { desenvolver através de } \\
\text { treinamentos }\end{array}$} \\
\hline \multicolumn{5}{|l|}{$\begin{array}{c}\text { Acredito que o } \\
\text { desenvolvimento dos } \\
\text { funcionários deva fazer } \\
\text { parte do plano } \\
\text { estratégico da empresa }\end{array}$} \\
\hline \multicolumn{5}{|l|}{$\begin{array}{l}\text { Entendo como } \\
\text { importante o feedback } \\
\text { do gestor }\end{array}$} \\
\hline \multicolumn{5}{|l|}{$\begin{array}{l}\text { Considero salário um } \\
\text { fator importante na } \\
\text { decisão de onde } \\
\text { trabalhar }\end{array}$} \\
\hline \multicolumn{5}{|l|}{$\begin{array}{l}\text { Procuro sempre } \\
\text { empresas que ofereçam } \\
\text { bons benefícios (vale } \\
\text { refeição, ginástica, } \\
\text { gasolina, } \\
\text { estacionamento, etc.) }\end{array}$} \\
\hline \multicolumn{5}{|l|}{$\begin{array}{l}\text { Prefiro procurar uma } \\
\text { empresa que tenha um } \\
\text { plano de carreira } \\
\text { estruturado }\end{array}$} \\
\hline \multicolumn{5}{|l|}{$\begin{array}{l}\text { Sairia da minha atual } \\
\text { empresa por não haver } \\
\text { oportunidade de } \\
\text { crescimento }\end{array}$} \\
\hline \multicolumn{5}{|l|}{$\begin{array}{l}\text { Considero importante } \\
\text { ter estabilidade e } \\
\text { equilíbrio entre vida } \\
\text { pessoal e profissional, } \\
\text { como férias, carga } \\
\text { horária flexível e home } \\
\text { office }\end{array}$} \\
\hline \multicolumn{5}{|l|}{$\begin{array}{l}\text { Considero importante } \\
\text { ter o reconhecimento } \\
\text { constante pelo meu } \\
\text { trabalho }\end{array}$} \\
\hline $\begin{array}{l}\text { Acredito que um bom } \\
\text { clima organizacional } \\
\text { impacta no meu } \\
\text { desempenho e nos } \\
\text { resultados da empresa }\end{array}$ & & & & \\
\hline
\end{tabular}




\section{Terceira parte}

Coloque em ordem de preferência os itens abaixo, de 1 a 7 , sendo 1 a sua maior preferência e 7 o item de menor preferências:

_ Treinamento e desenvolvimento para os funcionários

_ Qualidade de vida pessoal e profissional

_ Oportunidade de crescimento profissional

_ Remuneração e benefícios atrativos

_ Ambiente de trabalho agradável

_ Avaliação periódica de desempenho das atividades desempenhadas 